\title{
High altitude respiratory physiology and patho- physiology
}

\author{
Andrew Cumpstey ${ }^{1-4}$ \\ Michael P.W. Grocott ${ }^{2-4}$
}

1 NIHR Academic Clinical Fellow

2 Critical Care Research Area, Southampton NIHR Respiratory Biomedical Research Unit, Southampton, United Kingdom

${ }^{3}$ Anaesthesia and Critical Care Research Unit, University Hospital Southampton NHS Foundation Trust, Southampton, United Kingdom

${ }^{4}$ Integrative Physiology and Critical IIIness Group, Clinical and Experimental Sciences, Faculty of Medicine, University of Southampton, Southampton, United Kingdom

Address for correspondence:

Professor Michael P.W. Grocott

Critical Care Research Area

Southampton NIHR Respiratory Biomedical Research Unit

Southampton, United Kingdom

E-mail: mike.grocott@soton.ac.uk

\section{Summary}

At high altitude, reduced atmospheric pressure causes the partial pressure of oxygen to decrease creating an environment of hypobaric hypoxia which presents a unique set of challenges for the respiratory system. Pulmonary physiological responses such as the hypoxic ventilatory drive are essential for successful acclimatisation, whilst others such as hypoxic pulmonary vasoconstriction may be implicated in the development of altitude illnesses. Pulmonary conditions are some of the most common (e.g. high altitude cough) and also the most serious illnesses seen at altitude (e.g high altitude pulmonary oedema, HAPE). Minimising the chance of developing HAPE through planning an appropriate ascent profile should be strongly encouraged as HAPE can rapidly be fatal if left untreated. Whilst pharmacological agents such as nifedipine can help with the management of HAPE, rapid descent remains the single-most important treatment option once symptomatic. Given the increasing popularity of travelling to altitude, an awareness of how hypobaric hypoxia affects chronic respiratory conditions such as asthma and chronic obstructive pulmonary disease (COPD) is also becoming increasingly important for respiratory physicians.
KEY WORS: altitude, hypoxia, hypoxic, pulmonary oedema, acclimatisation, adaptation, cough, asthma, COPD, chronic obstructive pulmonary disease, hypobaric.

\section{Introduction}

High altitude presents a unique set of challenges for the respiratory system. With increasing altitude the air becomes colder and dryer and as barometric pressure falls, so too does the atmospheric partial pressure of oxygen $\left(\mathrm{P}_{\mathrm{AT}} \mathrm{O}_{2}\right)$. At $5300 \mathrm{~m}$ (the height of Everest base camp) there is only half of the amount of oxygen available for inspiration compared to sea level due to the lower atmospheric pressure $(1,2)$.

This hypobaric hypoxia causes a number of problems for over 100 million people who live, work or visit altitude environments every year (3). Physiological changes are detectable as low as $1500 \mathrm{~m}$ and altitude related illness is increasingly common at high altitude (defined as altitudes greater than $2500 \mathrm{~m}$ ) (4-6). Pulmonary conditions (e.g. lower respiratory tract infections and cough) are the most common medical conditions seen in altitude clinics, making a good understanding of respiratory pathophysiology at high altitude essential (7).

\section{Aims of this review}

The aims of this review are to explain the respiratory components of successful acclimatisation to altitude; describe the pathophysiology, prevention and management of common altitude-related respiratory illnesses such as high altitude pulmonary oedema (HAPE) and high altitude cough; and finally to offer an understanding of how hypobaric hypoxia affects chronic respiratory conditions such as asthma and chronic obstructive pulmonary disease (COPD). Searches were conducted on Medline and Web of Science databases using terms 'altitude' and 'pulmonary oedema' or 'cough' or 'respiratory illness' or 'asthma' or 'COPD'. Relevant articles were then selected (with particular focus given to articles published within the last 5 years) and the reference lists of identified articles were scrutinised.

\section{Acclimatisation}

The process of physiological adaptation to a high altitude environment is called acclimatisation and whilst some changes occur within minutes, others take days or weeks to be fully expressed $(1,4)$. Classical teaching 


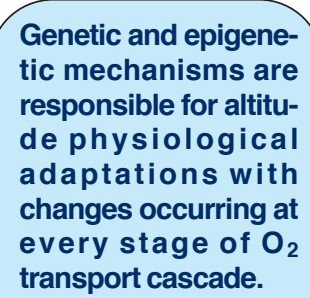

emphasises the importance of increased oxygen delivery to the peripheral tissues in this process, and indeed respiratory rate, heart rate, cardiac output and red cell mass do all increase as part of an early acclimatisation response $(4,8)$. However it is becoming increasingly clear that changes occur at every stage of the oxygen transport cascade with tissuelevel changes to the microcirculation and mitochondria being important $(9,10)$. Genetic (especially the HIF1a pathway) and epigenetic mechanisms are now recognised as being responsible for these physiological adaptations $(11,12)$. It has also become apparent that changes in oxygen utilisation may be at least as important as augmentation of oxygen delivery in the development of successful acclimatisation. Two physiological respiratory responses to hypoxia merit detailed discussion - the hypoxic ventilatory response and hypoxic pulmonary vasoconstriction.

\section{Hypoxic ventilatory response}

The hypoxic ventilatory response (HVR), believed to be one of the most important elements of acclimatisation, is the increase in ventilation trig-

gered by exposure to acute hypoxia. This response is non-linear with distinct phases. The initial increase in ventilation is classically explained by peripheral chemoreceptor stimulation. A decrease in the arterial partial pressure of oxygen $\left(\mathrm{PaO}_{2}\right)$ is detected in the glomus cells of the carotid
Hypoxia increased ventilatory response and decreased $\mathrm{PaCO}_{2}$ level. This reduces the overall respiratory drive, allowing return to normal capnia over 20 to $30 \mathrm{~min}$. bodies, resulting in increased stimulation of the central respiratory centres in the medulla and causing an increase in respiration rate $(R R)$, ventilation and $\mathrm{PaO}_{2}$. However, this increased ventilation also leads to a decrease in the arterial partial pressure of $\mathrm{CO}_{2}\left(\mathrm{PaCO}_{2}\right)$. This reduces the overall respiratory drive, causing this initial hypoxia driven response to be blunted and allows $\mathrm{PaCO}_{2}$ to tend back towards normality again over the next 20 to 30 minutes.

Respiratory acclimatisation occurs more gradually as both the HVR and the hypercapnic respiratory ventilatory response (HCVR) continue to increase over the following days to weeks although the exact mechanism behind these changes remains unclear. Metabolic compensation through renal bicarbonate loss may play a part but the time-course of this process does not match observed changes in ventilation $(8,13)$. An interesting hypothesis explaining why the HVR response has distinct acute and gradual phases relates to cerebral blood flow autoregulation, a well-recognised homeostatic phenomenon that conserves cerebral oxygen delivery $\left(\mathrm{DO}_{2}\right)$ by increasing blood flow in response to hypoxaemia. Whilst cerebral hypoxaemia is more normally due to increased metabolic activity resulting in higher cellular oxygen utilisation, Wolff notes that this autoregulatory response also serves to preserve $\mathrm{DO}_{2}$ when hypoxaemia is due to hypobaric hypoxia (i.e. at altitude) (14). He notes that maintenance of cerebral oxygenation during hypoxaemia occurs through hypoxic cerebral vasodilation resulting in elevated cerebral blood flows, but that this in turn will result in 'washout' of $\mathrm{CO}_{2}$. The resulting hypocapnia should tend to cause cerebral vessels to vasoconstrict and thereby blunt this initial response, but Wolff suggests that the hypoxic vasodilation response seems to outweigh this effect as overall flows increase, peaking at $8 \mathrm{hrs}$ after hypoxic exposure in his studies $(14,15)$. Local hypocapnia driven by increased cerebral blood flow results over time in reduced levels of bicarbonate ions as a buffering response with a new 'setpoint' being one candidate mechanism underpinning the HCVR (14). Wolff's hypothesis could neatly explain the different time-courses of phasic responses to hypoxia and also suggests that HVR is controlled centrally as opposed to peripherally with the main stimulus being to maintain cerebral oxygen delivery.

\section{Hypoxic pulmonary vasoconstriction}

As well as changes in HVR, decreases in $\mathrm{PaO}_{2}$ also cause the pulmonary vascular bed to rapidly constrict. Together with the increases in cardiac output described above, this hypoxic pulmonary vasoconstriction (HPV) results in increased pulmonary arterial pressures (8). Like HVR, HPV occurs within minutes of hypoxic exposure (16). It is thought to be mediated through oxygen sensitive voltage gated potassium channels in the pulmonary vasculature resulting in smooth muscle constriction - a widely conserved and beneficial response believed to have evolved to optimise ventilation perfusion matching by reducing blood flow to rela-
Tibetans exhale nitric oxide in much larger volumes and have a smaller hypoxic pulmonary vasoconstriction response than Western lowlanders. tively hypoxic alveoli (17). One important benefit of this is to facilitate the transition from fetal to neonatal circulation at the time of birth. When the fetal lungs are unventilated in utero and $\mathrm{PaO}_{2}$ is extremely low, HPV completely occludes pulmonary flow and diverts blood through the duetus arterioles into the fetal systemic circulation. However after the neonate's first breath this pulmonary hypoxaemia is rapidly reversed, pulmonary vasoconstriction decreases and the pulmonary circulation starts to open with flow being closely matched to the alveoli which are recruited first (to minimise shunting) until ultimately all of the alveoli are both ventilated and receiving pulmonary blood flow (17). However HPV may also have harmful consequences when global hypoxaemia results in widespread vasoconstriction. A brisk HPV is likely central to the pathogenesis of high altitude pulmonary oedema (HAPE), 
whilst having a normal or low HPV response seems protective against the condition $(18,19)$.

Interestingly, Tibetans - who are supremely adapted to living at altitude - have a larger hypoxic ventilatory response and a much smaller hypoxic pulmonary vasoconstrictive response than native lowlanders. This is possibly due to high levels of nitric oxide, a potent vasodilator which Tibetans exhale in much larger volumes than Western lowlanders (20).

\section{High altitude pulmonary oedema (HAPE)}

HAPE, first described in 1960, is a non-cardiogenic pulmonary oedema associated with heterogeneously elevated pulmonary artery pressure and consequent pulmonary capillary stress failure. This in turn causes leakage of protein and cell-rich fluid into the alveolar spaces impairing gas exchange. It typically occurs within 2-5 days of ascending to altitude $(8,21-23)$. Whilst classical-

ly occurring above $2500 \mathrm{~m}$ it

HAPE is the most common cause of medical evacuation from Everest base camp with an estimated mortality rate reportedly as high as $50 \%$ if not treated.

has also been described at altitudes as low as $1400 \mathrm{~m}$ (24). Quoted incidences depend on speed and magnitude of ascent but vary between $0.2 \%$ if $4500 \mathrm{~m}$ is reached in 4 days up to $15 \%$ if $5500 \mathrm{~m}$ is reached within 2 days (25). It is the most common cause of medical evacuation from Everest base camp (7) and one of the two most serious altitude related illnesses with an estimated mortality rate reportedly as high as $50 \%$ if not treated $(5,25)$. Native highlanders (including Tibetans/Sherpas) and experienced guides have also been described with the condition in the literature $(26,27)$.

HAPE can occur with or without preceding symptoms of acute mountain sickness (AMS) and whilst in severe cases patients can be feverish (up to $38.5^{\circ} \mathrm{C}$ ), dyspnoeic,
Rate of ascent has the strongest association with incidence of high altitude pulmonary edema. tachycardic, hypoxic and often coughing pink and frothy sputum; symptoms of mild disease may be as subtle as decreased performance with a dry cough. Consequently a high degree of suspicion is essential to aid early detection $(4,5,8)$.

\section{Risk factors}

Certain population groups have been suspected of having a genetic predisposition to developing HAPE (28). A recent review identified a number of possible gene mutations that may be linked to the pathogenesis and development of HAPE - many are downstream targets of HIF$1 \mathrm{a}$ and also involved in either HPV or HVR. These include the angiotensin-1 converting enzyme (ACE), vascular endothelial growth factor (VEGF), tyrosine hydroxylase (TH), serotonin transporter (5HTT), endothelin 1 (EDN1) and endothelial nitric oxide synthase (eNOS) genes (29). HAPE has also recently been associated with an overac- tive sympathetic nervous system, (30) the major-histocompatibility complex, (31) an increase in hepcidin levels (32) as well as lack of oestrogen (33).

What is certain though is that HAPE incidence increases at higher altitudes and particularly with more rapid rates of ascent - indeed rate of ascent has the strongest association with disease incidence (34). Young age and male gender are also both widely accepted risk factors and there is now growing evidence to suggest that an inter-current illness, particularly with a viral lower respiratory tract infection, also increases the risk of developing HAPE $(35,36)$.

\section{Prevention}

There has recently been significant interest amongst high altitude visitors in using low-level hypoxic chambers (most of which tend to generate a normobaric hypoxic environment through reducing the fractional oxygen concentration rather than altering barometric pressure) as a form of pre-acclimatisation to allow for a more rapid ascent profile later. This remains a very controversial area which is still being actively debated (37). However, recent data synthesis from a 2013 review evaluating the effectiveness of pre-acclimatisation strategies in acute mountain sickness, and a more recent systematic review comparing the physiological effects of normobaric and hypobaric hypoxia, suggest that normobaric hypoxia is not as effective at inducing acclimatisation as hypobaric hypoxic exposure and these two environments are not physiologically equivalent $(38,39)$.

Currently international guidelines from the Wilderness Medical Society do not support pre-acclimatisation, but rather recommend a slower ascent/longer acclimatisation as the best way to minimise the risk of developing altitude illnesses, including HAPE (40). Therefore planning appropriate itineraries should be actively encouraged and current recommendations suggest ascending no more than $500 \mathrm{~m}$ sleeping altitude each day once above $3000 \mathrm{~m}$ and including a rest day for every 3 to 4 days of ascent (40).

Pharmacological prevention and management of HAPE has focussed on reducing HPV. Nifedipine modified release $30 \mathrm{mg}$ twice a day is recommended as first line preventative therapy (41). Other agents such as tadalafil (10mg twice a day), dexamethasone (8mg twice a day) and salmeterol (in very high doses of $125 \mu \mathrm{g}$ twice a day, which may cause side effects) have all been shown to be effective in preventing HAPE in susceptible individuals in randomised control trials $(42,43)$. However, these trials were relatively small (29 and 37 subjects respectively) and clinical experience with these agents is limited. Consequently, these other agents are currently only recommended to be used as adjunctive therapies to nifedipine (40).

Theoretically acetazolamide (which encourages earlier bicarbonate diuresis through inhibiting renal carbonic anhydrase) should also prevent HAPE in the same way that it prevents other altitude illness (by accelerating acclimatisation), but this has not yet been realised in clinical trials $(40,44)$. Interestingly Acetazolamide has been shown to reduce HPV in dogs independently of its effects on carbonic anhydrase (45-47). 


\section{Management}

Descent remains the single most important treatment for anyone suspected of having HAPE (immediate increase in $\mathrm{PiO}_{2}$ ). Patients should aim to descend a minimum of 300-1000m, or until symptoms have fully resolved, with minimal exertion (e.g. ideally by mechanised or animal transport) as exertion can elevate pulmonary pressures and further worsen oedema $(4,5,40)$.

'Artificial descent' can be initiated temporarily by using a Portable Altitude Chamber (PAC) or 'Gamow' bag and this has been used successfully in cases of HAPE (48). However this should only be considered when actual descent is logistically impossible (e.g. due to inclement weather), as keeping the chamber pressurised is labour intensive, there are risks of baro-trauma to the ears and the patient is obliged to return to the pressure of the outside altitude/environmental pressure as soon as they leave the chamber. Furthermore, for very sick patients, access for medical interventions is delayed and this may result in harm (for example in the case of sudden loss of consciousness).

Supplemental oxygen should be given to patients if it is available, although this is often not possible outside of specialist altitude clinics. The $1^{\text {st }}$ pharmacological treatment is again nifedipine MR $30 \mathrm{mg}$ BD based on one randomised control trial and lots of international clinical experience (49). There is no good evidence to prove the effectiveness of using $\beta$-agonists (e.g. salmeterol), steroids (e.g. dexamethasone) or phosphodiesterase inhibitors (e.g. tadalafil) in the treatment of HAPE (40). However, in practice many HAPE patients are treated with many of these agents as adjuncts to nifedipine and most importantly descent where possible (26).

\section{High altitude cough}

High altitude cough is one of the most common presenting complaints in altitude clinics (7). It can result in serious consequences, such as fractured ribs, yet it remains very poorly understood and treatments remain remarkably limited $(50,51)$. This is at least in part due to a lack of research into the condition - the first study into high altitude cough was only published in 1994, more than 30 years after the first published description of HAPE (52). The aetiology of high altitude cough remains unclear. Initially the cough was thought

Cough is a common and debilitating symptom at high altitude, but its etiology remains unclear. to be due to altitude environments being cold and dry. However this was questioned when almost every subject in the Operation Everest II study developed worsening cough symptoms as the simulated altitude in the chamber increased beyond $7000 \mathrm{~m}$, despite the temperature and humidity both remaining tightly controlled (53). In a follow up chamber study, Operation Everest III, nocturnal cough frequency increased significantly in all 8 subjects at $5000 \mathrm{~m}$ compared to sea level and the citric acid cough threshold was significantly reduced at $8000 \mathrm{~m}$ (but interestingly not at $5000 \mathrm{~m}$ ), again despite tight control of chamber temperature and humidity (52). Changes in bradykinin levels and changes to the hypercapnic ventilatory response have both been proposed as possible aetiologies, but neither has shown positive correlations with altitude cough in studies $(54,55)$.

Another possibility is that altitude cough may simply be an early sign of subclinical acute mountain sickness (AMS) or even HAPE. However Mason argues strongly against this in his thorough review of altitude related cough, noting how it has rarely been observed as a major symptom in either clinical condition in multiple studies. Furthermore no association between cough and AMS or HAPE has ever been scientifically demonstrated (51).

The relationship between other causes of cough at sea level, such as inter-current viral illness or gastro-oesophageal reflux, and high-altitude cough have yet to be described at altitude (51). However neither of these mechanisms would easily explain the clear correlation between increasing altitude and worsening cough severity.

In summary, cough is common and debilitating at altitude. However its aetiology remains elusive and consequently no specific management advice can be given beyond trialling the many common treatments for symptomatic relief from chronic cough at sea level.

\section{Pre-existing lung disease at altitude}

\section{Asthma}

Living at high altitude for long periods seems to reduce the risk of developing asthma exacerbations. A study in Mexico has demonstrated an inverse relationship between asthma prevalence and altitude of residence in adults, and another study in Greece showed that the incidence of asthma halved in children living at 800$1200 \mathrm{~m}$ compared to sea level residents $(56,57)$. This may be due to reduced allergen exposure (e.g. to the house dust mite) at altitude, or possibly also due to the hypoxia driven increase in sympathetic tone, cortisol and catecholamine activity resulting in reduced bronchospasm and airway obstruction through increased $\beta 2$ receptor stimulation $(58,59)$.

However many of these studies are in long term altitude residents and there are still theoretical risks to the lowland asthma sufferers visiting altitude for short periods. Hypobaric hypoxia at altitude makes anyone feel breathless and this will be no different in asthma sufferers. As explained above, the increased ventilatory response to this stimulus will consequently also lower levels of carbon dioxide resulting in increased airway resistance (60). Breathing in cold dry air has also been shown to increase peripheral airway resistance proportionally more in asthmatic patients than in non-asthmatic controls (61). And finally, metered dose inhalers may also work less well at altitude due to the cold - emitting less of the drug and with increased particle size.

Different field studies have now independently shown that lowlanders with mild asthma can travel safely to the summit of Kilimanjaro $(5895 \mathrm{~m})$ and also to heights up to $6410 \mathrm{~m}$ in the Everest region of the Himalayas given ad- 
equate preparation and support $(59,62)$. Sensible precautions would be carrying extra supplies of inhaler medications and prednisolone to use in the event of symptoms worsening or an exacerbation developing, keeping inhalers as warm as possible and using a bandana/buff or something similar over the mouth might also help warm and humidify inspired air (60).

\section{Chronic Obstructive Pulmonary Disease (COPD)}

In contrast to asthma, it is widely acknowledged that living at altitude has harmful effects on COPD patients. Along with smoking, male gender and history of tuberculosis infection, living at altitude has been identified as an independent risk factor for developing COPD across Colombia and more recently in Peru, although both studies only looked at urban (large city) environments up to $2650 m(63,64)$. Furthermore, whilst living at altitudes above $1500 \mathrm{~m}$ in the US was generally associated with an increase in life expectancy compared to sea level, increased altitude had a harmful and dose-related effect in COPD patients who also had a significantly higher mortality at altitude (3-4 more per 10,000 compared to sea level) (65).

Altitude worsens both arterial hypoxaemia and pulmonary vasoconstriction in COPD patients. Although limited field studies have

In contrast to asthma, altitude has most harmful effects on COPD patients. been performed, one study in 1978 showed that resting $\mathrm{PaO} 2$ dropped to just $51.2 \mathrm{mmHg}$ within $3 \mathrm{hrs}$ of arriving at $1920 \mathrm{~m}$ altitude, and $\mathrm{PaO}_{2}$ universally dropped below 6.7 during light exercise in a more recent chamber study with a simulated altitude of $2438 \mathrm{~m}(66,67)$. Mean pulmonary artery pressure was significantly higher in COPD patients resident at an altitude of $1768 \mathrm{~m}$ compared to sea level $(36.05 \mathrm{mmHg}$ vs 26.78mmHg, p<0.001) (68).

Importantly, treatment of other altitude illness may also compound underlying COPD. Acetazolamide is one of the most commonly used pharmacological agents for both prevention and treatment of altitude related illness as explained above. However, through its direct inhibition of carbonic anhydrase it both increases ventilation and also inhibits carbon dioxide excretion, potentially resulting in worsening respiratory failure in patients with COPD. Consequently Luks and Swenson advise that if acetazolamide is to be used at all in these patients it should be used cautiously and the dose should be limited to just 125mg BD (69).

The British Thoracic Society guidelines on preparation of patients for air travel are a useful starting point for advice on how best to prepare patients for visiting altitude (airplane cabins often simulate altitudes of between 1500-2000m) (70). Patients with COPD who are considering high altitude travel should also consider carrying extra rescue medications (prednisolone and/or antibiotics) as well as spare inhalers; consider how remote their proposed destination is and ensure that their medical insurance will cover full evacuation and repatriation in the event of their condition worsening.

\section{Conclusion}

Hypobaric hypoxia can cause a number of pathophysiological respiratory problems, including some of the most common (e.g. cough) and the most serious (e.g. high altitude pulmonary oedema) altitude related ailments. Hypoxia at altitude can also have significant effects on chronic respiratory conditions such as chronic obstructive pulmonary disease. Further research is required to improve understanding of these conditions and refine treatments. Visitors to altitude should prepare carefully (e.g. planning appropriate ascents and ensuring adequate control of other conditions) before journeying to altitude to minimise risks as much as possible.

\section{Acknowledgements and statement of competing in-} terests

Dr. Andrew Cumpstey (AC) is funded in part through the NIHR Academic Clinical Fellowship scheme. Professor Michael P W Grocott (MPWG) is funded in part from the British Oxygen Company Chair of the Royal College of Anaesthetists, awarded by the National Institute of Academic Anaesthesia. Some of this work was undertaken at University Southampton NHS Foundation Trust - University of Southampton NIHR Respiratory Biomedical Research Unit which received a portion of funding from the UK Department of Health Research Biomedical Research Units funding scheme. MPWG has received honoraria for speaking for and/or travel expenses from BOC Medical (Linde Group). MPWG leads the Fit-4-Surgery research collaboration and the Xtreme- Everest Oxygen Research Consortium, which has received unrestricted research grant funding from (amongst other) BOC Medical (Linde Group) and Smiths Medical. All funding was unrestricted. The funders had no role in or preparation of the manuscript or the decision to publish.

\section{References}

1. Peacock AJ. Oxygen at high altitude. BMJ. 1998 Oct 17;317(7165):1063-6.

2. Grocott MPW, Martin DS, Levett DZH, McMorrow R, Windsor J, Montgomery HE. Arterial Blood Gases and Oxygen Content in Climbers on Mount Everest. N Engl J Med. 2009 Jan 8;360(2):140-9.

3. Burtscher M, Bachmann O, Hatzl T, Hotter B, Likar $\mathrm{R}$, Philadelphy $\mathrm{M}$, et al. Cardiopulmonary and metabolic responses in healthy elderly humans during a 1-week hiking programme at high altitude. Eur J Appl Physiol. 2001 May 1;84(5):379-86.

4. Imray $C$, Booth $A$, Wright $A$, Bradwell A. Acute altitude illnesses. BMJ. 2011 Aug 15;343:d4943.

5. Hackett PH, Roach RC. High-Altitude Illness. N Engl J Med. 2001 Jul 12;345(2):107-14.

6. Davis PR, Pattinson KTS, Mason NP, Richards P, Hillebrandt D. High Altitude Illness. J R Army Med Corps. 2005 Dec 1;151(4):243-9.

7. Némethy M, Pressman AB, Freer L, Mclntosh SE. Mt Everest Base Camp Medical Clinic "Everest ER": Epidemiology of Medical Events During the First 10 
Years of Operation. Wilderness Environ Med. 2015 Mar;26(1):4-10.

8. Luks AM. Physiology in Medicine: A physiologic approach to prevention and treatment of acute high-altitude illnesses. J Appl Physiol. 2015 Mar 1;118 (5):509-19.

9. Martin DS, Goedhart P, Vercueil A, Ince C, Levett $\mathrm{DZH}, \mathrm{Grocott}$ MPW, et al. Changes in sublingual microcirculatory flow index and vessel density on ascent to altitude. Exp Physiol. 2010 Aug 1;95(8):880-91.

10. Levett DZ, Radford EJ, Menassa DA, Graber EF, Morash AJ, Hoppeler $\mathrm{H}$, et al. Acclimatization of skeletal muscle mitochondria to high-altitude hypoxia during an ascent of Everest. FASEB J. 2012 Apr 1;26(4):1431-41.

11. Semenza GL. Hypoxia-Inducible Factors in Physiology and Medicine. Cell. 2012 Feb 3;148(3):399-408.

12. Martin DS, Gilbert-Kawai E, Levett DZ, Mitchell K, Bc RK, Mythen MG, et al. Xtreme Everest 2: unlocking the secrets of the Sherpa phenotype? Extreme Physiol Med. 2013 Oct 23;2(1):30.

13. West JB, Schoene RB, Luks AM, Milledge JS. High altitude medicine and physiology. Fifth. CRC Press; 59-81 $\mathrm{p}$.

14. Wolff CB. Cerebral Blood Flow and Oxygen Delivery at High Altitude. High Alt Med Biol. 2000 Mar 1;1(1): 33-8.

15. Wolff CB, Barry P, Collier DJ. Cardiovascular and respiratory adjustments at altitude sustain cerebral oxygen delivery - Severinghaus revisited. Comp Biochem Physiol A Mol Integr Physiol. 2002 May; 132 (1):2219.

16. Talbot NP, Balanos GM, Dorrington KL, Robbins PA. Two temporal components within the human pulmonary vascular response to $\sim 2 \mathrm{~h}$ of isocapnic hypoxia. J Appl Physiol. 2005 Mar 1;98(3):1125-39.

17. Moudgil R, Michelakis ED, Archer SL. Hypoxic pulmonary vasoconstriction. J Appl Physiol. 2005 Jan 1;98(1):390-403.

18. Hopkins SR, Garg J, Bolar DS, Balouch J, Levin DL. Pulmonary Blood Flow Heterogeneity during Hypoxia and High-Altitude Pulmonary Edema. Am J Respir Crit Care Med. 2005 Jan 1;171(1):83-7.

19. Dehnert C, Mereles D, Greiner S, Albers D, Scheurlen F, Zügel S, et al. Exaggerated Hypoxic Pulmonary Vasoconstriction Without Susceptibility to High Altitude Pulmonary Edema. High Alt Med Biol. 2015 Mar;16(1):11-7.

20. Wu T, Kayser B. High Altitude Adaptation in Tibetans. High Alt Med Biol. 2006 Sep 1;7(3):193-208.

21. Houston CS. Acute pulmonary edema of high altitude. N Engl J Med. 1960 Sep 8;263:478-80.

22. Hultgren HN, Lopez CE, Lundberg E, Miller H. Physiologic Studies of Pulmonary Edema at High Altitude. Circulation. 1964 Mar 1;29(3):393-408.

23. Hultgren HN M. High-altitude pulmonary edema: Current Concepts. Annu Rev Med. 1996;47(1):267-84.

24. Gabry AL, Ledoux X, Mozziconacci M, Martin C. High-altitude pulmonary edema at moderate altitude $(<2,400 \mathrm{~m} ; 7,870 \text { feet })^{\star}$ : A series of 52 patients. Chest. 2003 Jan 1;123(1):49-53.

25. Bärtsch P, Swenson ER. Acute High-Altitude Illness- es. N Engl J Med. 2013 Jun 13;368(24):2294-302.

26. Jones BE, Stokes S, McKenzie S, Nilles EJ, Stoddard GJ. Management of HAPE in the Himalaya: a review of 56 cases presenting at Pheriche Medical Aid Post (4240m). Wilderness Environ Med. 2013 Mar;24(1):32-6.

27. Yanamandra U, Patyal S, Mukherji R, Nair V. Highaltitude pulmonary oedema in native highlanders. BMJ Case Rep. 2014 Jan 27;2014:bcr2013202513.

28. Whitlow KS, Davis BW. High Altitude Pulmonary Edema in an Experienced Mountaineer. Possible Genetic Predisposition. West J Emerg Med. 2014 Nov;15 (7):849-51.

29. Bhagi S, Srivastava S, Singh SB. High-altitude Pulmonary Edema: Review. J Occup Health. 2014;56 (4):235-43.

30. Duplain H, Vollenweider L, Delabays A, Nicod P, Bärtsch P, Scherrer U. Augmented Sympathetic Activation During Short-Term Hypoxia and High-Altitude Exposure in Subjects Susceptible to High-Altitude Pulmonary Edema. Circulation. 1999 Apr 6;99(13):1713-8.

31. Hanaoka M, Kubo K, Yamazaki Y, Miyahara T, Matsuzawa Y, Kobayashi T, et al. Association of High-Altitude Pulmonary Edema With the Major Histocompatibility Complex. Circulation. 1998 Mar 31;97(12): 1124-8.

32. Altamura $S$, Bärtsch $P$, Dehnert $C$, Maggiorini $M$, Weiss G, Theurl I, et al. Increased hepcidin levels in high-altitude pulmonary edema. J Appl Physiol. 2015 Feb 1;118(3):292-8.

33. Luks AM. A Novel Risk Factor for High Altitude Pulmonary Edema? Wilderness Environ Med. 2014 Dec $1 ; 25(4): 490-2$.

34. Bärtsch $P$, Mairbäurl $H$, Maggiorini M, Swenson ER. Physiological aspects of high-altitude pulmonary edema. J Appl Physiol. 2005 Mar 1;98(3):1101-10.

35. Shrestha P, Pun M, Basnyat B. High altitude pulmonary edema (HAPE) in a Himalayan trekker: a case report. Extreme Physiol Med. 2014 Mar 17;3:6.

36. Schoene RB. ILInesses at high altitude* . Chest. 2008 Aug 1;134(2):402-16.

37. Comments on Point:Counterpoint: Hypobaric hypoxia induces/does not induce different responses from normobaric hypoxia. J Appl Physiol. 2012 May 15;112(10):1788-94.

38. Fulco CS, Beidleman BA, Muza SR. Effectiveness of Preacclimatization Strategies for High-Altitude Exposure. Exerc Sport Sci Rev. 2013 Jan;41(1):55-63.

39. Coppel J, Hennis P, Gilbert-Kawai E, Grocott MP. The physiological effects of hypobaric hypoxia versus normobaric hypoxia: a systematic review of crossover trials. Extreme Physiol Med. 2015 Feb 26;4(1):2.

40. Luks AM, Mclntosh SE, Grissom CK, Auerbach PS, Rodway GW, Schoene RB, et al. Wilderness Medical Society Practice Guidelines for the Prevention and Treatment of Acute Altitude Illness: 2014 Update. Wilderness Environ Med. 2014 Dec 1;25(4):S4-14.

41. Bartsch P, Maggiorini M, Ritter M, Noti C, Vock P, Oelz O. Prevention of High-Altitude Pulmonary Edema by Nifedipine. N Engl J Med. 1991 Oct 
31;325(18):1284-9.

42. Maggiorini M, Brunner-La Rocca H-P, Peth S, Fischler M, Böhm T, Bernheim A, et al. Both Tadalafil and Dexamethasone May Reduce the Incidence of HighAltitude Pulmonary EdemaA Randomized Trial. Ann Intern Med. 2006 Oct 3;145(7):497-506.

43. Sartori C, Allemann Y, Duplain H, Lepori M, Egli M, Lipp E, et al. Salmeterol for the Prevention of HighAltitude Pulmonary Edema. N Engl J Med. 2002 May 23;346(21):1631-6.

44. Imray C. Acetazolamide for the prophylaxis of acute mountain sickness. BMJ. 2012 Oct 31;345:e7077.

45. Höhne C, Krebs MO, Seiferheld M, Boemke W, Kaczmarczyk G, Swenson ER. Acetazolamide prevents hypoxic pulmonary vasoconstriction in conscious dogs. J Appl Physiol. 2004 Aug 1;97(2):515-21.

46. Swenson ER. Carbonic anhydrase inhibitors and hypoxic pulmonary vasoconstriction. Respir Physiol Neurobiol. 2006 Apr 28;151(2-3):209-16.

47. Höhne C, Pickerodt PA, Francis RC, Boemke W, Swenson ER. Pulmonary vasodilation by acetazolamide during hypoxia is unrelated to carbonic anhydrase inhibition. Am J Physiol - Lung Cell Mol Physiol. 2007 Jan 1;292(1):L178-84.

48. Freeman K, Shalit M, Stroh G. Use of the Gamow Bag by EMT-basic park rangers for treatment of high-altitude pulmonary edema and high-altitude cerebral edema. Wilderness Environ Med. 2004;15 (3):198201.

49. Oelz O, Ritter M, Jenni R, Maggiorini M, Waber U, Vock $P$, et al. Nifedipine for high altitude pulmonary oedema. The Lancet. 1989 Nov 25;334(8674):12414.

50. Litch J, Tuggy M. Cough Induced Stress Fracture and Arthropathy of the Ribs at Extreme Altitude. Int J Sports Med. 1998 Apr;19(03):220-2.

51. Mason NP. Altitude-related cough. Cough Lond Engl. 2013 Oct 31;9:23.

52. Barry PW, Mason NP, Riordan M, O'Callaghan C. Cough frequency and cough-receptor sensitivity are increased in man at altitude. Clin Sci Lond Engl 1979. 1997 Aug;93(2):181-6.

53. Houston CS, Sutton JR, Cymerman A, Reeves JT. Operation Everest II: man at extreme altitude. J Appl Physiol. 1987 Aug 1;63(2):877-82.

54. Mason NP, Petersen M, Mélot C, Kim EV, Aldashev A, Sarybaev A, et al. Changes in plasma bradykinin concentration and citric acid cough threshold at high altitude. Wilderness Environ Med. 2009;20(4):353-8.

55. Thompson AAR, Baillie JK, Bates MGD, Schnopp MF, Simpson A, Partridge RW, et al. The citric acid cough threshold and the ventilatory response to carbon dioxide on ascent to high altitude. Respir Med. 2009 Aug 1;103(8):1182-8.

56. Vargas MH, Sienra-Monge JJ, Díaz-Mejía G, DeLeónGonzález M. Asthma and geographical altitude: an inverse relationship in Mexico. J Asthma Off J Assoc Care Asthma. 1999 Sep;36(6):511-7.

57. Gourgoulianis KI, Brelas N, Hatziparasides G, Papayianni M, Molyvdas P-A. The Influence of Altitude in Bronchial Asthma. Arch Med Res. 2001 Sep;32 (5):429-31.
58. Grootendorst DC, Dahlén S-E, Van Den Bos JW, Duiverman EJ, Veselic-Charvat M, Vrijlandt EJLE, et al. Benefits of high altitude allergen avoidance in atopic adolescents with moderate to severe asthma, over and above treatment with high dose inhaled steroids. Clin Exp Allergy. 2001 Mar 1;31(3):400-8.

59. Stokes S, Kalson N, Earl M, Frost H, Whitehead AG, Tyrrell-Marsh I, et al. Bronchial asthma on Mount Kilimanjaro is not a disadvantage. Thorax. 2008 Oct 1;63(10):936-7.

60. Luks AM, Swenson ER. Travel to high altitude with pre-existing lung disease. Eur Respir J. 2007 Apr $1 ; 29(4): 770-92$.

61. Kaminsky DA, Irvin CG, Gurka DA, Feldsien DC, Wagner EM, Liu MC, et al. Peripheral airways responsiveness to cool, dry air in normal and asthmatic individuals. Am J Respir Crit Care Med. 1995 Dec 1;152(6):1784-90.

62. Huismans HK, Douma WR, Kerstjens HAM, Renkema TEJ. Asthma in Patients Climbing to High and Extreme Altitudes in the Tibetan Everest Region. J Asthma. 2010 Jul 16;47(6):614-9.

63. Caballero A, Torres-Duque CA, Jaramillo C, Bolívar F, Sanabria F, Osorio P, et al. PRevalence of copd in five colombian cities situated at low, medium, and high altitude (prepocol study)* ${ }^{*}$ Chest. $2008 \mathrm{Feb}$ $1 ; 133(2): 343-9$.

64. Jaganath D, Miranda JJ, Gilman RH, Wise RA, Diette $\mathrm{GB}$, Miele $\mathrm{CH}$, et al. Prevalence of chronic obstructive pulmonary disease and variation in risk factors across four geographically diverse resource-limited settings in Peru. Respir Res [Internet]. 2015 [cited 2015 Apr 26];16(1). Available from: http://www.ncbi. nlm.nih.gov/pmc/articles/PMC4389577/.

65. Ezzati M, Horwitz MEM, Thomas DSK, Friedman AB, Roach R, Clark T, et al. Altitude, life expectancy and mortality from ischaemic heart disease, stroke, COPD and cancers: national population-based analysis of US counties. J Epidemiol Community Health. 2012 Jul 1;66(7):e17-e17.

66. Graham WG, Houston CS. Short-term adaptation to moderate altitude. Patients with chronic obstructive pulmonary disease. JAMA. 1978 Sep 29;240(14): 1491-4.

67. Christensen CC, Ryg M, Refvem OK, Skjonsberg $\mathrm{OH}$. Development of severe hypoxaemia in chronic obstructive pulmonary disease patients at 2,438 m (8,000 ft) altitude. Eur Respir J. 2000 Apr 1;15 (4):6359.

68. Güvenç TS, Erer HB, Kul Ş, Perinçek G, İlhan S, Sayar N, et al. Right Ventricular Morphology and Function in Chronic Obstructive Pulmonary Disease Patients Living at High Altitude. Heart Lung Circ. 2013 Jan;22(1):31-7.

69. Luks AM, Swenson ER. MEdication and dosage considerations in the prophylaxis and treatment of highaltitude illness*. Chest. 2008 Mar 1;133(3):744-55.

70. Ahmedzai S, Balfour-Lynn IM, Bewick T, Buchdahl R, Coker RK, Cummin AR, et al. Managing passengers with stable respiratory disease planning air travel: British Thoracic Society recommendations. Thorax. 2011 Sep 1;66(Suppl 1):i1-30. 